\title{
VOCES DE LO FANTÁSTICO EN LA NARRATIVA ESPAÑOLA CONTEMPORÂNEA.DAVID ROAS Y ANA CASA. 2016.
}

Maira Angélica Pandolfi

Recebido em 07 abr 2017. Maira Angélica Pandolfi é Doutora em Letras (2006) Aprovadoem 03 mar 2017. e Professora Assistente da Universidade Estadual Paulista - Unesp, no campus de Assis. Realizou Estágio de Pesquisa (2013) na Universidad de Salamanca, na Espanha, estudando o Mito de Don Juan e sua representação nas literaturas de língua espanhola e na literatura brasileira. Participa da Associação Brasileira de Hispanistas (ABH), da Associação Internacional de Cervantistas, do GT ANPOLL "Vertentes do Insólito Ficcional", do "Grupo de Estudos Linguísticos" e, também, dos Grupos de Pesquisa, cadastrados no Diretório de Grupos do CNPq, "Narrativas Estrangeiras Modernas", "Vertentes do Fantástico na Literatura", "Grupo de Estudos Bakhtinianos". Tem como área de investigação: Literatura Comparada (Literatura Espanhola, Literatura Hispano-Americana, Literatura Brasileira); Mitos Literários; Romance Histórico; Literatura Fantástica e Policial; Adaptações da Literatura ao cinema; Adaptações de clássicos da literatura espanhola à literatura infantojuvenil.

CV: http://lattes.cnpq.br/5248539478534906 
Voces de lo fantástico en la narrativa española contemporânea (2016) é uma obra de David Roas e Ana Casas a qual 12 trabalhos, publicados entre os anos de 2005 e 2014, que pretende oferecer ao leitor uma breve história do fantástico espanhol, desde 1980 até os dias atuais. Nessa obra são elencados os principais autores e obras que compreendem o mencionado período.

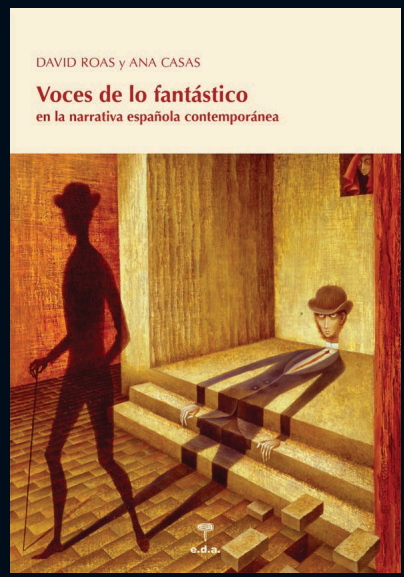
Os primeiros capítulos, portanto, oferecem um panorama de autores, obras e características histórico-culturais que propiciaram o auge e o reconhecimento do gênero fantástico na Espanha a partir da década de 80. Nos primeiros cinco anos desse período, escritores iniciantes como Cristina Fernández Cubas, que logo ocuparia um lugar central no gênero, e outros já consagrados como José María Merino e Alfonso Sastre, publicaram contos e romances ambientados em torno dos paradigmas da literatura fantástica; uma forma literária que até esse momento ainda era, segundo Roas e Casas, desprestigiada pela crítica, pelo universo acadêmico e relegada, enfim, à condição de subliteratura. Com a regularidade das publicações de cunho fantástico e a boa acolhida por parte dos leitores, da crítica e, sobretudo, do mundo editorial, inaugura-se na Espanha o que os autores denominam de "anos de normalização" do gênero fantástico, que teve como valor principal o reconhecimento dessa vertente literária pela academia (esse tema foi discutido por Roas e Casas no Prólogo da antologia La realidad oculta: Cuentos fantásticos españoles del siglo XX, 2008). Ao longo 
de duas décadas (1980 a 2000) são publicadas diversas obras onde aparecem inúmeros contos, alguns romances e uma expressiva produção de microcontos fantásticos. Esta última modalidade tem sido considerada uma via comum de manifestação do fantástico na literatura contemporânea espanhola como comprovam os seguintes títulos: La piedra Simpson (1987), de Alberto Escudero; Historias mínimas (1988), de Javier Tomeo; Escaleras en el limbo (1991), de Agustín Cerezales; La sombra del Obelisco (1993), de Rafael Pérez Estrada; Kískili-Káskala (1994), de Julia Otxoa; Noticia de tierras improbables (1994), de Pedro Ugarte; Los males menores (1993), de Luis Mateo Díez; Los dichos de un necio (1996), de David Roas; Cuentos a la intempérie (1997), de Juan José Millás; e El muchacho amarillo (2000), de Rafael Pérez Estrada.

Sobre os escassos romances fantásticos do período supracitado predominam os de extensão mais breve, de autores como José María Merino, Pilar Pedraza, Cristina Fernández Cubas, Juan José Millás e Juan Pedro Aparicio.

$\mathrm{Na}$ trajetória do gênero fantástico espanhol, iniciada timidamente a partir dos anos 60 e, de forma mais incisiva, a partir de 1980, acontecem muitas transformações que marcam, principalmente a partir dos anos 80 , a retomada, a renovação e o reconhecimento acadêmico, editorial e do público leitor da literatura fantástica. Muitos são, portanto, os fatores que contribuíram para a concretização dessa nova fase: a renovação das formas de narrar e um esplendor do gênero conto, principal veículo de manifestação do fantástico; o predomínio da fantasia frente ao realismo social e à literatura de testemunho; a negação da opinião corrente de que a literatura espanhola sempre havia sido essencialmente realista. 
É válido ressaltar também que a literatura de Kafka, Borges e Cortázar tiveram uma decisiva importância no desenvolvimento e difusão de novas formas e motivos que caracterizam a literatura fantástica espanhola, além da retomada editorial de alguns mestres do gênero como Hoffmann, Poe, Maupassant, Stoker, Machen, Lovecraft. Contribuíram, ainda, para a popularização e prestígio da literatura fantástica na Espanha, as produções cinematográficas e algumas séries de televisão transmitidas a partir das décadas de 60 e 70. Todos esses elementos unidos ao êxito que tiveram alguns teóricos do fantástico como Roger Caillois, Tzvetan Todorov, Irène Bessière, estimularam a pesquisa sobre a história desse gênero em território espanhol. Apesar de tudo, para entender o boom da literatura fantástica na Espanha das décadas de 80 e 90 e sua diferença em relação à literatura fantástica produzida em décadas anteriores, Roas e Ana Casas assinalam dois aspectos fundamentais: uma "nova" concepção do real e do indivíduo e, diretamente relacionado a isso, a incorporação de novos temas e recursos para expressar essa visão de mundo.

O avanço da física einsteiniana, da mecânica quântica, da filosofia construtivista e novas tecnologias não deixaram espaço para a perpetuação da crença em uma realidade objetiva. Ao contrário, surgiu um novo paradigma que passou a conceber a realidade como algo instável, caótico, descentralizado, enfim, algo construído culturalmente e em permanente questionamento. Nesse estado de coisas, manifesta-se a literatura fantástica, que tem como um dos principais objetivos a desestabilização de alguns limites, a fusão de mundos paralelos em uma aparente normalidade; a "desfamiliarização" daquilo que antes se considerava familiar; a 
irrupção do insólito em situações cotidianas. Essa desestabilização do real como ideia central da literatura fantástica contemporânea vem sempre acompanhada de uma crise de identidade que se reflete na presença de um ser humano perdido, desarraigado e inadaptável. Essas transformações, no entanto, não anulam o viés de algumas convenções formais que fazem parte de uma tradição do gênero fantástico. A narrativa dos anos 80 e 90 obteve grande êxito na revigoração dos temas e dos recursos dessa vertente literária pela via da metaficção e da transgressão linguística. Como exemplo de êxito no manejo inovador desses recursos formais e temáticos os autores de Voces de lo fantástico dedicam o segundo e o terceiro capítulos à escritora espanhola Cristina Fernández Cubas e suas obras; autora que se destacou na década de 1980 com a publicação de seus primeiros livros de contos: Mi hermana Elba (1980) e Los altillos de Brumal (1983). De acordo com Roas e Casas, seus livros geram um duplo desconforto: metafísico e hermenêutico. O inquietante de suas narrativas é destacado pelos referidos críticos, não tanto por sua dimensão fantástica e abominável, mas, sobretudo, porque parece instaurar o que Umberto Eco chamou de "obra aberta", evidenciando, assim, o caráter inacabado e ambíguo de seus relatos e exigindo do receptor maior participação no ato interpretativo. Um dos elementos constantemente referido por Roas e Casas no que concerne à apreensão do fenômeno fantástico em obras contemporâneas é a presença da dimensão prosaica, familiar e cotidiana que sofre a interferência de algo inexplicável ou impossível, resultando em um abalo dessa dimensão e na desestabilização de nossa tradicional concepção do real. Dessa maneira, instaura-se na narrativa uma 
perspectiva insólita, uma nova e inquietante maneira de interpretar a realidade que se apresenta e seus fenômenos. Em todo conjunto da obra de Cristina Fernández Cubas (contos, romances e até em sua peça de teatro Hermanas de sangre) é perceptível a presença dessa dimensão perturbadora. Para uma melhor compreensão da poética fantástica da autora, Roas e Casas sugerem a leitura do conto "La noche de Jezabel", presente na obra Los altillos, de Brumal. O conto trabalha o caráter metaficcional e reúne relatos que contemplam tópicos convencionais do gênero fantástico como espectros, fantasmas e espíritos. No entanto, o grande diferencial reside na forma surpreendente com que a autora (re)organiza esses elementos convencionais, pois uma das narradoras é um fantasma que se infiltra disfarçadamente no meio dos demais narradores e emite juízos de valor sobre as histórias contadas por eles. Em seu jogo metaficcional, Cubas parece brincar com os efeitos que as histórias de fantasma produzem sobre um fantasma, pois as reações e opiniões deste revelam a poética fantástica da própria escritora. Além do efeito metaficcional, o elemento da surpresa é outro recurso utilizado por Cristina Fernández Cubas com o intuito de romper as expectativas do leitor, visto que a figura mais excêntrica do relato é a que leva o nome mais prosaico, Laura, e não o nome mais esdrúxulo, Jezabel. É nítida, também, a impressão de um matiz gótico em grande parte de sua obra, mas Roas e Casas advertem, contrariando a opinião de alguns críticos que intitulam pejorativamente a obra de Cubas de "gótica", que a inovação não reside no uso de elementos tradicionais e recorrentes, mas na forma com que esses elementos tradicionais são reorganizados pela literatura contemporânea de corte fantástico. A recorrência 
do macabro e do gótico na obra de Cristina Fernández Cubas, por exemplo, não indica falta de originalidade, mas, antes de tudo, uma grande habilidade e frescor no manejo renovado desses elementos convencionais e que guardam muitos ecos de grandes mestres como Poe e H. P. Lovecraft.

Os autores David Roas e Ana Casas assinalam, ao longo dos comentários críticos sobre as obras analisadas, que o caráter perturbador, instaurador do caos, das incertezas e do despertar para uma realidade que até o momento havia estado oculta ou desconhecida das personagens é uma característica desse gênero que, além disso, tem a função de suscitar reflexões metafísicas ao imprimir o inusitado na vida rotineira e ordenada. Esse inusitado representa, muitas vezes, a nudez de uma realidade abominável que abruptamente atravessa nosso caminho, podendo gerar, inclusive, momentos de autoconhecimento.

O terceiro capítulo, também dedicado à obra de Cristina Fernández Cubas, comenta relatos de seu primeiro livro de contos, Mi hermana Elba (1980), enfocando a categoria personagem. Os críticos procuram demonstrar, com exemplos diversificados, a habilidade da escritora em subverter, relativizar, tornar difusa ou ambígua a figura monstruosa; tópico convencional dentro do gênero fantástico. Uma das técnicas empregadas por Cubas reside no fato de tornar a realidade muito mais complexa do que aparenta ser, estendendo ao máximo o fio conector dos acontecimentos para que o final da narrativa possa concentrar uma abertura capaz de sugerir muitas e até contraditórias interpretações. Suas histórias privilegiam situações de conflito, muitas delas sobre o embate entre indivíduos ou entre o indivíduo e o mundo, retomando o 
tópico do motivo do "duplo" de uma forma diferenciada ao colocar em evidência o desencontro das personagens com elas mesmas, como se estivessem fora do eixo, desencaixadas, desproporcionais, assimétricas, enfim, semelhantes aos perfis humanos das pinturas cubistas. Assim como ocorre na narrativa fantástica, que subverte a opinião convencional e cristalizada sobre o mundo, o homem e seu comportamento por meio do uso diferenciado das próprias formas e motivos convencionais, também se valem Cézanne e Picasso dos objetos na pintura cubista, não se utilizando destes do mesmo modo que a pintura tradicional, mas recolocandoos em um novo espaço perturbador, de ruptura com o equilíbrio renascentista. É essa nova reorganização e utilização dos objetos na pintura cubista que nos insere na perspectiva de uma visão múltipla e ambígua dos mesmos, ao contrário da visão unívoca predominante na perspectiva renascentista. A ampliação do campo de visão que a pintura cubista proporciona em sua aproximação insólita dos objetos parece exercer a mesma função poética que, em nosso modo de ver, exerce "La ventana del jardín", primeiro relato de Cristina Fernández Cubas, como comprova o comentário crítico de Roas e Casas (p.51): "En 'La ventana del jardín' vemos cuestionadas las fronteras de la normalidad (y por extensión, los limites de la monstruosidad, pues ambas nociones no tienen aqui un sentido unívoco)". A complexidade pode estar nas coisas mais simples do cotidiano, pois quando o insólito componente da literatura fantástica perturba nossos sentidos conseguimos obter uma compreensão mais ampla dos fenômenos ao nosso redor que antes passavam desapercebidos. Quando isso acontece, estamos diante do que os autores de Voces de lo fantástico definem no 
terceiro capítulo dessa obra: a epifania. Somente por meio dos momentos epifânicos é que as personagens podem se reencontrar e se auto-reconhecer.

No que diz respeito ao capítulo 4: "La persistencia de lo cotidiano. Verosimilitud e incertidumbre fantástica en la narrativa breve de José María Merino", os autores discutem questões cruciais para se pensar e repensar a literatura fantástica contemporânea, bem como aspectos que a diferenciam de suas origens mais longínquas no romance gótico inglês do século XVIII. As reflexões sobre a narrativa fantástica e sobre o pacto de leitura são colocadas em destaque pelos autores, com comentários que aludem aos estudos que David Roas realizou em sua obra $A$ ameaça do fantástico - aproximações teóricas, traduzida ao português por Julián Fuks e publicada pela Editora Unesp em 2014. Nesta, Roas (2014, p.166) afirma que a passagem do romance gótico ao conto fantástico romântico ilustra perfeitamente o processo acentuado de cotidianização desses relatos. No século $\mathrm{XIX}$, o realismo se intensificou nos contos fantásticos, como ocorreu na narrativa de Edgar Allan Poe. Esse procedimento na literatura espanhola pode ser notado em algumas leyendas de Gustavo Adolfo Bécquer, autor cujo estilo parece ter muitos pontos em comum com José María Merino, seja pela ocorrência de fenômenos extraordinários em espaços geográfico-culturais reais, seja pelas marcas da tradição literária oral em alguns relatos, semelhante ao que ocorre nas leyendas becquerianas, seja pela presença do medo ou de finais ambíguos em algumas narrativas. Embora esses aspectos comparativos não tenham sido explorados por Roas e Casas, estes também reconhecem ecos de Bécquer na produção de Merino e 
denominam de becquerianos os contos "Los valedores" e "Genarín y el gobernador". No entanto, enquanto em leyendas como "La ajorca de oro", de Bécquer, o fenômeno insólito, inexplicável, que caracteriza o fantástico, pode ter seu desenlace considerado como ambíguo se considerarmos as visões oníricas do protagonista Pedro Alfonso de Orellana sob o ponto de vista racional, explicadas como frutos do medo causado por sua ação transgressora ao roubar a Virgem do Sacrário ou, simplesmente, como produtos do fantástico puro, fenômeno inexplicável pela razão, isso não corresponde ao desenlace de muitos contos de José María Merino em sua obra Cuentos del reino secreto. Nessa obra, o fenômeno sobrenatural é aceito ao final, por parte das personagens e dos leitores, como algo incontestável, porém incompreensível para os mesmos. Isso não significa aceitação absolutamente normal do fenômeno sobrenatural, como postula Soldevila, com o qual Roas e Casas estão em desacordo, visto que se assim fosse o fantástico de Merino cairia no terreno do maravilhoso, de acordo com a definição de Todorov. Até mesmo a tradicional definição de fantástico de Todorov, ainda de ampla aceitação pela crítica atual, é cuidadosamente questionada por Roas e Casas, pois enquanto Todorov considera a vacilação do leitor, ou seja, a dúvida, como fundamental à irrupção do fantástico, os autores da obra aqui comentada reclamam a necessidade de revisão dessa definição com base no estudo da literatura fantástica contemporânea, como a de José María Merino, onde em muitos relatos não há duas explicações possíveis ao fenômeno extraordinário, visto que o absurdo é algo que se impõe à nossa realidade, sem possibilidade de racionalização, mas que também não quer dizer que há uma aceitação crédula de tal fenômeno por 
parte das personagens. Nesses relatos, muitas vezes, o aspecto extraordinário não é explicado pelos narradores, para que o leitor possa ter uma intervenção mais ativa nesse processo, atuando como árbitro final. Nesse sentido, Roas e Casas são categóricos, pois na opinião dos autores o texto fantástico exige continuamente que o leitor confronte a realidade empírica à realidade textual vivenciada pelas personagens, sem possibilidade de desconsiderar uma delas no processo interpretativo. Nesse sentido, a interpretação do fantástico parece ser inerente à interpretação que temos do real, característica que requer, portanto, uma constante revisão, visto que a realidade pode ser concebida das mais diversas maneiras em distintas culturas, espaços e tempos históricos.

O comentário crítico dos autores demonstra que o texto fantástico contemporâneo guarda sempre a seguinte mensagem: fazer-nos recordar que somos seres automatizados, alienados e muito pouco acostumados a conceber o oculto como universo possível e natural de convívio cotidiano e que, talvez, seja essa função do texto fantástico: proporcionar uma experiência insólita capaz de desautomatizar o homem moderno. Esse processo de "(des)alienação" ou “(des)automatização" no qual estamos imersos somente é possível, nos dias de hoje, por meio do "hiperrealismo" (termo que segundo Roas e Ana Casas significa cotejar a realidade do leitor com a realidade das personagens), visto que o fantástico não significa necessariamente a fuga da realidade, como se costuma ingenuamente classificá-lo. O capítulo 5 trata de pontuar essa problemática, acrescentando que um dos eixos fundamentais do fantástico contemporâneo reside na "crise de identidade". Assim, esse capítulo intitulado "Souto, o la búsqueda imposible" se 
restringe ao enfoque da personagem Eduardo Souto, um professor que protagoniza diversos relatos do escritor José María Merino. Em algumas produções nas quais essa personagem aparece, se empreende uma busca impossível de sentido da linguagem, cuja pretensão reside em querer revelar a ordem que estaria por trás de diversas manifestações linguísticas. Nesse intento de querer classificar o inclassificável, Rosas e Casas aludem constantemente à ironia borgiana, que concebe o universo como fruto do acaso, fato que condena ao fracasso todo intento racional de explicação de uma ordem universal. A obsessão linguística de Souto é análoga à loucura de Julio, protagonista criado por Juan José Millás na obra El orden alfabético (1998), onde este enfrenta um mundo que vai perdendo seu sentido conforme ocorre a progressiva desaparição da linguagem. Contudo, no conto de Merino quem desaparece é Souto. As aventuras de Souto, conforme paráfrase realizada por Roas e Casas, são alusões aos grandes projetos quixotescos, quase sempre fadados ao fracasso, dos quais a literatura brasileira está plenamente povoada, desde Policarpo Quaresma, no romance Triste fim de Policarpo Quaresma, de Lima Barreto, à loucura fantásticomirabolante das personagens de Álvaro Cardoso Gomes, a exemplo de seu romance Concerto Amazônico. Assim como a personagem Vicente Holgado, que figura em relatos da obra Ella imagina, de Juan José Millás, o protagonista de Concerto Amazônico também opta por inventar uma realidade distinta daquela em que vive, realizando uma ruptura radical com o tempo cronológico para projetar uma nova e absurda realidade à sua realidade cotidiana, que é reflexo da realidade do leitor. Assim sendo, Roas e Ana Casas descrevem Vicente Holgado como um tipo obsessivo e inadaptado 
que em relatos como "La mujer del cuadro" consegue viver dentro de um quadro, rompendo com a dimensão espacial empírica admitida pelo leitor. Já no romance brasileiro de Álvaro Cardoso Gomes surge um protagonista-narrador que rompe com a nossa lógica temporal e faz coexistirem personagens de quinhentos anos de história brasileira e mundial, promovendo, assim, um grande encontro entre elas, somente possível no plano temporal fantástico da realidade literária inventada pelo autor para confrontar os limites de nossa percepção cronológica de tempo.

O capítulo 6 "El hombre que (casi) controlaba el mundo. Juan José Millás y lo fantástico" volta-se para a apresentação das excêntricas personagens de Juan José Millás que, quixotescamente, conseguem recriar uma nova realidade à altura de seus transbordantes anseios, pois estes não cabem nos limites da percepção do real comumente admitidos por nós.

A influência de Kafka ecoa significativamente na produção fantástica espanhola de Javier Tomeo. O capítulo 7 "Monstruos, alucinados y prodígios: la ambiguedad fantástica en la obra de Javier Tomeo" trata de elucidar essa dupla vinculação do escritor com as formas do fantástico e do absurdo. Apoiando-se nas reflexões de Rosalba Campra, autora de El relato fantástico en España e Hispanoamérica (1991), Roas e Ana Casas esclarecem que na vertente do absurdo o mundo representado aparece alterado em todos os seus elementos, enquanto na vertente fantástica o impossível é percebido como um acontecimento extraordinário, que se choca com a concepção de real predominante no texto, organizado à imagem e semelhança da realidade empírica do leitor. Por essa razão, o que distingue a obra de Tomeo é o cruzamento 
de ambas vertentes e, consequentemente, um grau maior de naturalização dos elementos insólitos. Essa nova configuração minimiza, portanto, a sensação de ameaça do fantástico e faz com que a alegoria apareça de forma mais evidente. A obra de Tomeo, segundo Roas e Ana Casas, está povoada de monstros, muitos deles na forma de seres mitológicos, que representam a visão pessimista do autor sobre o homem e suas relações interpessoais. Outra representação recorrente na obra de Tomeo são as personagens portadoras de alguma deformação física que optam pelo delírio como forma de vida. Seus romances enfatizam o viés psicológico das personagens questionadoras de seu próprio "eu" e das convenções circundantes, como ocorre em El canto de las tortugas e La noche del lobo. Outras vezes a dimensão fantástica é revelada em suas narrativas mais breves, que se aproximam das fábulas, uma vez que são protagonizadas por animais ou vegetais, como ocorre nas obras: Bestiario (1989), Zoopatías y zoofilias (1992), El nuevo Bestiario (1994) e Los reyes del huerto (1994). Embora sua expressiva produção transite mais pelo terreno do alegórico, onde predominam as formas do absurdo, o romance La ciudad de las palomas é o mais interessante, segundo Roas e Casas, do ponto de vista de uma transgressão fantástica em sentido estrito, pois a obra apresenta dois planos mais definidos que se chocam: o da realidade cotidiana, que se identifica com a realidade do leitor, e o plano do inexplicável, que invade o cotidiano do protagonista de forma inquietante e ameaçadora.

A presença do fantástico na narrativa breve espanhola tem em Javier Marías outra voz de destaque, sobretudo, pela forma inovadora com que o escritor retoma o tema tradicional do gênero 
"ghost story" ou narrativa de fantasma. De acordo com os críticos, no capítulo 8 "Perdidos en Redonda: Javier Marías y lo fantástico", a importante presença do fantástico nessas narrativas manifesta-se em oito contos de Marías que privilegiam o fantasma e o duplo. Roas e Casas enfocam os contos de temática fantasmal, de Javier Marías: "La vida y la muerte de Marcelino Iturriaga" (1968), "La dimisión de Santiesteban" (1975), "Una noche de amor" (1989), "Cuando fui mortal" (1993), "No más amores" (1995) e "Serán nostalgias" (1998). Na tradição do gênero "ghost story", a figura do fantasma está comumente ligada a uma imagem terrífica, ameaçadora e perturbadora do mundo dos vivos. Ainda que Marías esteja inserido nessa tradição, uma parte de seus relatos representa uma guinada nessa convenção, propondo uma relação harmoniosa entre vivos e mortos. Em alguns contos como "Una noche de amor" a relação fantasmal desencadeia uma relação sexual entre o protagonista e o fantasma feminino; tema que nos remete, na literatura brasileira, aos contos fantásticos de Noite na Taverna (1855), de Álvares de Azevedo. Essa visão mais integradora e positiva do fantasma ganha outros matizes em contos como "La vida y la muerte de Marcelino Iturriaga" (1968) e "Cuando fui mortal" (1993), onde o fantasma se transforma em narrador de sua própria história. Nessa perspectiva, a condição fantasmal funciona quase como uma lupa, aumentando o campo de visão do narrador-protagonista, com revelações surpreendentes sobre si mesmo, cujo conhecimento lhe chega somente a partir dessa nova condição.

$\mathrm{Na}$ literatura brasileira, o motivo do fantasma autor é contemplado por Machado de Assis em Memórias Póstumas de Brás Cubas (1881), no qual o protagonista deseja escrever sua 
autobiografia. Segundo Roas e Casas, esse mesmo motivo não era habitual na literatura fantástica, aparecendo em poucos contos como: "El espectro" (1921) e "Más allá"(1925), de Horacio Quiroga; "El fantasma” (1946), de Enrique Anderson Imbert, e "The Portobello Road" (1960), de Muriel Spark. Na literatura espanhola, o motivo do fantasma-autor é um tópico recorrente na narrativa de Javier Marías e foi expresso, em sua melhor versão, no conto "Cuando fui mortal" (1993). Para os críticos, quando Marías atribui o foco narrativo de sua própria história ao fantasma ele o humaniza mais, além de identificá-lo com a figura de escritor, acentuando, assim, a nostalgia de seu estado anterior e minimizando a alteridade fantasmal, geralmente concebida como ameaçadora.

Outra dimensão fantástica apontada no capítulo 9 "Lo fantástico siniestro en la narrativa breve de Ignacio Martínez de Pisón" referese à presença do elemento "estranho" ou "abominável", conceituado por Freud em 1919. Esse aspecto terrífico que se impõe por meio do estranho desponta em meio do entorno familiar, muitas vezes, como fruto do acaso. Um dos contos de Martínez Pisón, "Otra vez en la noche", sugere uma correspondência entre a aparição de morcegos na vida da personagem Sílvia e seus sentimentos. É o narrador que, nesse caso, começa a demonstrar estranhamento diante do acúmulo de morcegos na casa de Sílvia. Esta, por sua vez, apresenta-se no relato como uma pessoa de comportamento introvertido, solitária e propensa ao delírio. A narrativa breve "Alguien te observa en secreto" também está povoada de figuras excêntricas e tem como objetivo ressaltar aspectos reprimidos da psique dessas personagens. De acordo com os críticos, nos contos de Martínez de Pisón o "outro", o "estranho" que habita o interior 
das personagens, se revela e ao revelar-se expõe experiências traumáticas vivenciadas por elas. É na projeção desse "estranho", dos monstros da psique, ou seja, na fronteira entre o patológico e o fantástico que o insólito se revela, pois Roas e Casas consideram que o insólito é sempre um desafio ao pensamento racional. Diferentemente de outras narrativas, em alguns contos de Pisón as personagens aceitam mais naturalmente o fenômeno impossível e se adaptam resignadamente a essa nova realidade insólita que se impõe; fato que não dispensa o efeito abominável, inerente ao fantástico, resultando em um final trágico para muitas delas. São histórias que evidenciam procedimentos irônicos e paródicos, já comentados por Roas ao tratar da nova narrativa fantástica em sua obra Tras los límites de lo real. Una definición de lo fantástico (2011).

Nos capítulos finais de Voces de lo fantástico os autores apresentam um conjunto de vozes de escritores nascidos entre 1960 e 1975 que se dedicam ao cultivo do gênero fantástico como forma privilegiada de expressar uma diversidade de temas e estilos, bem como preocupações estéticas e ideológicas que caracterizam a pósmodernidade. Defender a existência expressiva e significativa de uma literatura fantástica, desde o Romantismo até os dias atuais, não tem sido uma tarefa fácil, segundo Roas e Casas, pois grande parte da crítica literária cultiva, ainda, o hábito errôneo de considerar o realismo como uma característica que define a literatura espanhola, desconsiderando autores canônicos que se empenharam no cultivo do gênero fantástico, como Espronceda, Zorrilla, Alarcón, Bécquer, Galdós, Pardo Bazán, Pío Baroja, Valle-Inclán, Unamuno, Max Aub, Alfonso Sastre, Juan Benet e Javier Marías. Esse conjunto de novos escritores da literatura fantástica tanto devem aos canônicos 
como também às estrelas contemporâneas que contribuíram para a consolidação e difusão do fantástico a partir da década de 80: Fernández Cubas, Merino, Millás ou Tomeo, que beberam nas fontes de Borges e Cortázar, escritores de referência na língua espanhola que, por sua vez, devem muito a Poe, Maupassant e Kafka. Apesar da grande contribuição literária dos canônicos, a nova geração de narradores fantásticos é fruto de uma educação intermidiática, pois são escritores formados também pelo universo audiovisual do cinema, da televisão, dos desenhos animados e vídeo games. Entre os diversos aspectos que caracterizam a poética fantástica dos autores atuais, Roas e Casas enumeram os quatro mais importantes, amplamente comentados nos capítulos anteriores. Os quatro aspectos que se apresentam como dominantes são: a justaposição conflituosa de paradigmas sobre o real; a alteração de identidades (novas variantes do tema do duplo, a metamorfose e a animalização); o recurso de dar voz ao "outro", de converter em narrador um ser fantasmal; o fantástico e o humor.

Nos dois últimos capítulos, os autores se detêm nos aspectos formais (a vinculação do gênero fantástico às formas narrativas breves como o conto e o microconto; este último como uma forte tendência no fantástico espanhol contemporâneo); aspectos linguísticos e temáticos. Um dos temas mais recorrentes nos microcontos é o tópico do duplo, tomado a partir de uma perspectiva irônica. Em suas narrativas breves, abordam esse tema com notáveis resultados autores como Juan Eduardo Zúñiga, Luis Mateo Díez, Julia Otxoa, José María Merino e David Roas.

O último capítulo da obra enfoca o microconto e a reescritura fantástica do mito. Nessa modalidade, o principal destaque fica por 
conta do fenômeno da intertextualidade; caracterizada, sobretudo, pelos espaços de silêncio que devem ser preenchidos pelo leitor. As obras fantásticas onde predomina a presença do conteúdo mitológico também são comentadas pelos autores que observam nessa característica um componente de transgressão discursiva e ideológica. Nos relatos mitológicos sobressaem aspectos como a ausência de conflito entre o conteúdo mitológico e o contexto onde ocorrem os acontecimentos, assim como a presença de um tempo indeterminado. O desajuste que o fantástico sempre impõe às narrativas, nesse caso, é problematizado da seguinte forma, ou seja, o conteúdo moral exemplar que deve moldar uma coletividade na narrativa mitológica é subvertido a partir da irrupção do fantástico. Assim, o fantástico surge a partir do conflito gerado entre o relato mitológico e a realidade cotidiana, (re)atualizando o sentido primitivo do mito ao transportá-lo a um contexto histórico diferente daquele em que foi gerado, e atribuindo-Ihe novos e perturbadores significados, geralmente pautados na paródia, e outros diversos procedimentos retóricos como a supressão, a substituição, a ampliação de elementos e as mudanças de foco narrativo.

Para finalizar, Voces de lo fantástico en la narrativa española contemporánea merece destaque não apenas por seu cuidadoso trabalho de reunir o conjunto de autores e obras mais significativos do gênero na atualidade, com detalhadas paráfrases críticas que despertam no leitor o intenso desejo de degustar página por página desses insólitos relatos, como também por seu caráter crítico sobre a configuração discursiva dessa modalidade literária. Além disso, David Roas não é apenas um dos mais relevantes especialistas no estudo da literatura fantástica na Espanha, mas também um 
dos expoentes literários de maior prestígio no rol de escritores espanhóis contemporâneos que renovaram, em muitos aspectos, a narrativa de corte fantástico. 